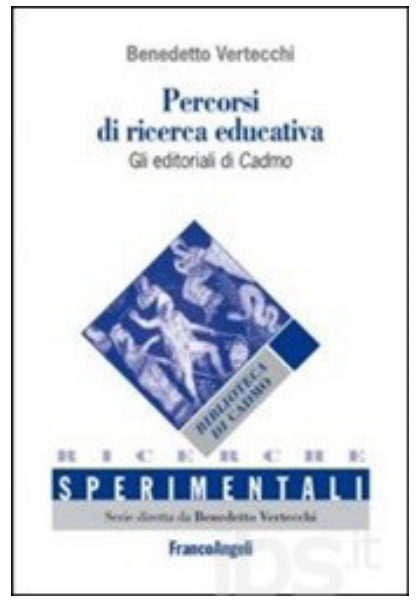

Itinerarios de investigación educativa. Los editoriales de Cadmo

Benedetto Vertecchi

Año: 2014

Lugar: Milán

Editorial: Franco Angeli. Páginas: 132

ISBN: 978-88-917-0633-1

\title{
El sonido de las palabras escritas del hombre sabio
}

Benedetto Vertecchi es ante todo un hombre sabio. Me apasiona escuchar a gente inteligente y erudita, desde la infancia, desde que era un niño. Siempre he admirado a las personas que, siendo juiciosas y prudentes, en la mayoría de los casos humildes, saben comunicar sus ideas a través de la conversación, de la palabra, implicando en su oratoria a quienes somos cómplices afortunados de sus disquisiciones e interpretaciones. Más aún si estas personas son pensadores humanistas a quienes el tiempo, el buen hacer y la paciencia han convertido en auténticos referentes morales y profesionales. Lo he reflejado en entrevistas y artículos, puede que con mayor rotundidad en el volumen dedicado al profesor de estética en la Universitat de València y crítico de arte Romà de la Calle, a quien considero un verdadero maestro. En el caso de Vertecchi, profesor de la Università Roma Tre, editor y fundador de la revista Cadmo. Giornale Italiano di Pedagogias perimentale. An International Journal of Education Research, la fascinación pasa por la doble oportunidad de haber podido escucharle en persona, y ahora tener la ocasión de continuar leyendo sus trabajos a través de una colección que ha creado para la Editorial Franco Angeliy que lleva por nombre Biblioteca de Cadmo. Research in Education. Una de las peculiares características de esta nueva colección es que se editan en versión bilingüe, utilizando dos idiomas, que en este caso son el italiano y el español.

Al leer las aportaciones de Vertecchi en esta reciente entrega no puedo dejar de recordar las palabras de Nuccio Ordine, quien en su célebre ensayo La utilidad de lo inútil. Manifiesto, llega a pronosticar que en los próximos años habrá que esforzarse por salvar de la deriva utilitarista no sólo la ciencia, la escuela y la universidad, sino también todo lo que llamamos cultura. Dice Ordine, poniendo en duda los paradigmas dominantes del beneficio, que sólo el saber puede ser compartido sin empobrecer, más bien al contrario, ya que enriquece a quien lo transmite y a quien lo recibe. Y si eso es cierto, o se aproxima a una cierta verdad, todo lo que aprendemos de Vertecchi acaba convirtiéndonos en seres más reflexivos, más honestos y más críticos. 
Nuestro autor creó el Laboratorio di Pedagogia Sperimentale de la Università Roma Tre y empezó a publicar Cadmo en 1993. Ha sido testigo de los cambios que se han experimentado en Italia (y en Europa) durante las últimas décadas, tanto a nivel educativo como desde la perspectiva política que adquiere cada momento histórico. Esto le permite plantear un análisis pausado y concienzudo de todo aquello que ha venido marcando la pauta neoliberal que se asume desde los postulados europeístas oficiales. Creo que la voz de Vertecchi recoge muy bien una cuestión clave: mientras los responsables políticos andaban metidos en planificar una educación absolutamente liberal y economicista, tanto los académicos más implicados como la mayoría de la población con espíritu crítico observaban cómo se perdía la oportunidad de establecer nuevas prácticas educativas en un ambiente muy marcado por las tecnologías. Tanto es así, que Vertecchi se arma de valor en un determinado momento para defender la escritura manual, es decir la caligrafía, como un modelo de tecnología muy vinculado a los saberes y a las formas de pensamiento, como una habilidad presuntamente manual pero muy enraizada en la facultad de asumir conocimiento. Lo cierto es que el profesor Vertecchi, muy familiarizado con la innovación y la experimentación, apuesta por los valores humanistas, o mejor aún, por los valores de la humanidad, frente a un exagerado paradigma consumista de tintes prácticamente absurdos y desde luego abusivos.

Lo que nos ofrece el recopilatorio es una selección de textos escritos para los editoriales de la revista Cadmo, habiendo elegido algunos de los más recientes, justamente por tratar aspectos más vinculados a la actualidad. Cadmo es una publicación que, al contrario de lo que ocurre en la mayoría de casos, ofrece la posibilidad de enviar originales en diferentes idiomas (italiano, español, inglés, francés, alemán,...). Esto marca la personalidad de Cadmo, ya que es uno de los pocos casos de revistas con mucho prestigio (indizada en ISI, Scopus) que no se decanta por un único idioma, sino que pone en valor la variedad babélica. En total son ocho los editoriales recopilados, que comprenden el periodo entre 2003 y 2013. La decisión de haber preparado esta reseña para una revista especializada en educación artística reside en el hecho de que Vertecchi elabora un discurso muy propio de las humanidades, y ene se sentido, sus palabras resultarán muy beneficiosas para quienes nos dedicamos a la educación en artes.

En Reconstruir la casa de Salomón, el primero de los editoriales recopilados, nuestro profesor reconsidera la importancia que tuvo en su momento una de las tesis clave de la reforma luterana, a saber, el principio de libre examen, mediante el cual se reconocía el derecho y el deber de todo cristiano de leer e interpretar autónomamente la Biblia, lo cual suponía, en realidad, una apuesta para que los cristianos supiesen leer. Ahí radicaba una de las claves de la revolución de la imprenta y de la transmisión de saberes durante varios siglos. El dominio de las capacidades alfabéticas es una de las temáticas que más han interesado siempre a nuestro catedrático, que se siente más humanista que pedagogo, y para quien la utopía de Lutero se basa en la argumentación de un género argumentativo centrado 
en la negación del espacio (u-topía, es decir, no lugar). Según el profesor Vertecchi, en un sistema como el que preparó la UE cuando lanzó el Plan Bolonia, ya no se mira a los estudios y la investigación como a un bien cuyo valor es intrínseco, sino que se juzgan positivamente solo en función de sus resultados económicos. Recuerda nuestro investigador que autores como George Orwell o AldousHuxley demostraron al respecto que contaban con una capacidad de pre-representación no inferior a la de los utopistas clásicos, teniendo en cuenta que en sus visiones aparentemente futuristas, la educación ocupa un papel primordial. En cualquier caso, asistimos a una mutación de la educación, que pasa a ser una especie de ingeniería social cuyos objetivos son una pura y dura utilización de recursos de los individuos con el objeto de adaptarlos a los procesos de acumulación de riqueza de unos pocos.

Los títulos de los ocho editoriales seleccionados son todos suculentos, si bien para ir cerrando la recensión me centraré en tres de ellos: La cultura del prejuicio, El engaño y Educar la creatividad con creatividad. Dice el autor que un prejuicio es un juicio expresado antes que un hecho determinado suceda, se hayan constatado las circunstancias y observado sus efectos. En educación, el conocimiento sigue siendo, principalmente, efecto de la confirmación. Pero las políticas más reaccionarias no admiten esta apabullante realidad, y promueven una ordenación del sistema educativo donde predomina la separación precoz entre el alumnado, algo que acarrea consecuencias no solamente en los destinos sucesivos de los alumnos, sino también en la calidad de la oferta de instrucción. Esta situación determina que en el plano cultural todas las decisiones estén sometidas a las modas del momento, y si últimamente el énfasis se ha puesto en la tecnología, la cultura de empresa o el inglés, lo cierto es que se viene demostrando que esta obcecación no ha sido motivo de mejoras educativas, sino más bien de logros políticos y económicos. En El engaño nos habla nuestro autor de la obsesión de determinados círculos de poder por ofrecer enseñanza superior únicamente a unos pocos elegidos (algo que ya hizo hipócritamente el ministro fascista Gentile en 1923). Conviene observar de qué manera evolucionan los estudios universitarios, ya que es cada vez menor el número de estudiantes que emprenden estudios científicos (no confundir con tecnológicos), al tiempo que se utiliza a los estudiantes como números útiles para obtener recursos. Todo ello nos lleva a una situación de farsa, ya que las familias que asocian el que sus hijos obtengan una licenciatura con la coronación de una cumbre que significa elevación social, se topan con un engaño.

Finalmente, y puede que solamente por este editorial valiese la pena traer la recensión a EARI, el profesor Vertecchi dedica una reflexión más que adecuada al tema de la creatividad, aspecto que tradicionalmente ha venido vinculándose a las enseñanzas artísticas. Si bien todo el mundo afirma que se debe consentir a niños y jóvenes que saquen a la luz las potencialidades con que cuentan, también lo es que partes cada vez más significativas de la experiencia en la edad de desarrollo están sometidas a procesos de condicionamiento cuyos objetivos nada tienen que 
ver con la revelación de las potencialidades de cada cual. Esto sucede más aún cuando se ofrece a una parte del alumnado la salida hacia la formación profesional. $\mathrm{Y}$ en ese sentido parece claro que lo que se aprende en la escuela solo es útil cuando satisface las exigencias del sistema económico. Y por tanto, ¿qué sentido tiene empeñarse en ofrecer una cultura que carece de implicaciones prácticas a muchos jóvenes destinados a desempeñar actividades subalternas y repetitivas? No creo que Vertecchi siga los mismos pasos que sus colegas norteamericanos Giroux, Postman o Chomsky, pero lo cierto es que sus palabras suenan a postulados cercanos a los que plantean estos analistas. Opina que en un mundo complejo, ser ciudadano se está convirtiendo en una tarea nada fácil, ya que la literatura, el arte, la historia o la música son sustancialmente inútiles, puesto que no sirven para las actividades productivas. Sin embargo, ¿estamos seguros de que no son precisamente estas inutilidades lo realmente útil para calificar el perfil no solo de las minorías acomodadas, sino del conjunto de la población, y que la capacidad de producir un pensamiento autónomo no deriva de un pensamiento no enquistado en fórmulas reproductivas, según esquemas que no dejan espacios de libertad?.

Ricard Huerta. Universitat de València 